\title{
A Facile Synthesis of Glycerol Carbonate by Transesterification of Glycerol with Dimethyl Carbonate: Ceria Based Catalysts
}

\author{
Venkatesh ${ }^{1,2,3}$, Sathgatta Zaheeruddin Mohamed Shamshuddin,,$^{1,2^{*}}$, Srinivasa Raghavendra \\ Pratap ${ }^{1,2,3}$ \\ ${ }^{1}$ Chemistry Research Laboratory, HMS Institute of Technology, NH4, Kyathsandra, Tumakuru, Karnataka. \\ ${ }^{2}$ Research and Development Centre, Bharathiar University, Coimbatore, \\ ${ }^{3}$ Channabasaveshwara Institute of Technology, Gubbi.
}

* Corresponding author: Sathgatta Zaheeruddin Mohamed Shamshuddin. Phone: +91-9844718742, email: mohamed.shamshuddin@gmail.com

Received April 13 ${ }^{\text {th }}, 2018$; Accepted August 21 ${ }^{\text {st }}, 2018$.

DOI: http://dx.doi.org/10.29356/jmcs.v62i4.859

\begin{abstract}
Solid base catalysts such as Ceria-Zirconia-Magnesia with different mole ratio of magnesium were prepared by impregnation method and characterized by $\mathrm{CO}_{2}$-TPD, PXRD, FT-IR and ICP-OES analysis. The catalytic activity of the catalysts was tested in the liquid phase transesterification of glycerol with dimethyl carbonate to synthesise glycerol carbonate. Optimization of reaction condition was carried out by varying the molar ratio of the reactants, temperature and time. The highest yield $(97 \%)$ of glycerol carbonate was obtained at a reactant molar ratio of $1: 3$ at $120^{\circ} \mathrm{C}$ in $6 \mathrm{~h}$. Study of reusability and reactivation of solid base catalyst was also taken up. A suitable base catalysed mechanism for the formation of glycerol carbonate is proposed.
\end{abstract}

Keywords: Glycerol; Ceria/Zirconia/Magnesia; Glycerol carbonate; Transesterification.

Resumen. Se prepararon catalizadores de base sólida como Ceria-Zirconia-Magnesia con diferentes proporciones molares de magnesio mediante el método de impregnación y se caracterizaron por análisis de $\mathrm{CO}_{2}$-TPD, PXRD, FT-IR e ICP-OES. La actividad catalítica de los catalizadores se probó en la transesterificación en fase líquida de glicerol con carbonato de dimetilo para sintetizar carbonato de glicerol. La optimización de las condiciones de reacción se llevó a cabo variando la relación molar de los reactivos, la temperatura y el tiempo. El mayor rendimiento ( $97 \%$ ) de carbonato de glicerol se obtuvo a una relación molar reactiva de $1: 3$ a $120{ }^{\circ} \mathrm{C}$ en $6 \mathrm{~h}$. También se realizó un estudio de la reutilización y reactivación del catalizador de base sólida. Se propone un mecanismo catalítico básico adecuado para la formación de carbonato de glicerol.

Palabras clave: Glicerol; Ceria/Zirconia/Magnesia; Carbonato de Glicerol; Transesterificación.

\section{Introduction}

Glycerol is the major by-product obtained from the biodiesel industry by transesterification of fatty acid with methanol. Hence the conversion of glycerol to a value added product by different reaction pathways is desirable and has become a broad area of research [1]. Glycerol carbonate (GC) is widely used as a solvent, curing agent in cement plasticizer, humectants and nail lacquer gel in the cosmetic industry. Glycerol carbonate is also used as membrane component in gas separation, the electrolyte in lithium-ion batteries, as a component in detergents, etc. It also finds indirect applications in the preparation of surfactants, 
polymers as well as chemical intermediates in organic synthesis $[1,2]$. Different reagents are used to prepare glycerol carbonate (GC) from glycerol such as $\mathrm{CO}, \mathrm{CO}_{2}$, phosgene, urea and organic carbonates. Due to toxicity of $\mathrm{CO}$ and phosgene their usage is practically limited in both industries and laboratory scales [3-5]. Direct reaction of $\mathrm{CO}_{2}$ with glycerol is thermodynamically limited and gives a very low yield even under drastic conditions [6,7]. The drawback of synthesizing GC from glycerol and urea is the formation of large amount of ammonia and inseparable by-products like isocyanic acid and biuret [8,9]. Use of ethylene carbonate in the synthesis of GC is an attractive approach, but separation of ethylene glycol from GC is difficult due its high boiling point [10]. However the use of dimethyl carbonate as a carbonating agent has many advantages like simple procedure, mild condition and easy separation, is considered as the promising approach for industrial application [11, 13]. It was observed that basic catalysts were more active than the acidic catalyst and activity of the catalyst was dependent on the basicity of the catalyst as reported by Ochoa et al [10]. Transesterfication of glycerol with dimethyl carbonate in presence of solid basic catalyst under solvent free condition is carried out to avoid the by-product formation. This method also avoids extraction and removal of the catalyst from the reaction mass [14]. Keeping in view the disadvantages of homogenous catalyst, heterogenous base catalyst are preferred in organic synthesis.

By the virtue of red-ox and acid-base properties, ceria is an important metal oxide used as a catalyst or a catalyst support [15]. Moreover ceria is a multifunctional as well as a promising catalytic material for a wide range of technological applications, including heterogeneous catalysis. However ceria as a solid base or solid acid is not extensively studied [16]. As a heterogeneous catalyst, ceria exhibits excellent catalytic performance in reactions, such as dehydration of alcohols [17] reduction of carboxylic acid [18] and alkylation of aromatic compounds [19]. Ceria-zirconia mixed oxides enrich red-ox as well as acid-base properties [16]. Compared to mono metal oxides, mixed metal oxides have been largely used as heterogeneous catalyst, due to their strong basic property and surface area. Mixed metal oxide catalysts have several advantages like activity over a wide range of temperature. The solid base catalyst is extensively used as a support or as a active phase. Metal oxides and mixed metals are widely used as solid acid / base catalyst in various organic transformations, due to their acid / base or red-ox properties. Ceria is used as a solid catalyst in various organic syntheses such as dehydrogenation of alcohols, carbonate synthesis etc, due to its Lewis acid and stronger Lewis base property respectively [20,21]. Incorporation of zirconia cat ion into ceria unit cell and vice versa changes the surface area of acid-base site. $\mathrm{Zr}^{+4}$ ion $\& \mathrm{Ce}^{+4}$ ion acts as Lewis acid sites, $\mathrm{O}^{-2}$ ions as Lewis or Brønsted base sites [22].

In the present work, a series of mixed metal oxide catalysts such as Ceria-ZirconiaMagnesium having different $\mathrm{Mg}$ (II) content were prepared and evaluated for the catalytic activity to the synthesis of glycerol carbonate by transesterfication of glycerol with dimethyl carbonate. These catalysts were prepared by impregnation method and characterized by $\mathrm{CO}_{2}$-TPD, PXRD and FT-IR techniques. The effect of molar ratio of the reactant, temperature, weight of the catalyst and reaction time was investigated. Reactivation and reusability of the catalyst was also studied.

\section{Experimental}

\section{Materials and Methods}

Zirconyl nitrate and ceric ammonium nitrate were supplied by Sigma Aldrich, India, Ltd. Glycerol, dimethyl carbonate and magnesium nitrate were procured from SD Fine Chemicals, India, Ltd.

\section{Preparation of catalysts}

Preparation of catalysts was achieved by preparing ceria-zirconia-magnesia mixed oxide with the mole ratio (1:1:1, 1:1:2, 1:1:3) by impregnation method. Known amounts of ceric ammonium nitrate, zirconyl nitrate and magnesium nitrate, were typically dissolved in a small quantity of distilled water and the resulting paste was dried in an oven at $1200 \mathrm{C}$ for $12 \mathrm{~h}$ and calcined for $5 \mathrm{~h}$ at $6500 \mathrm{C}$. These catalysts were represented as CZM-111, CZM-112 and CZM-113 respectively, where the numbers represent the mole ratio of the metal oxide. 


\section{Characterisation of catalysts}

The crystallinity was analyzed by obtaining Powder X-ray diffraction (PXRD) patterns recorded on an X-ray powder diffractometer (Philips X'pert) using $\mathrm{CuK} \alpha$ radiation $(\lambda=1.5418 \AA)$ over graphite crystal monochromator. Measurement of basicity of the catalyst was carried out by CO2-TPD method on a Mayura TPD unit, FT-IR spectra were recorded in the range of 500-4000 cm-1 using $\mathrm{KBr}$ pellets on a Nicolet spectrometer.

\section{Catalytic activity of catalyst ( Transesterification of glycerol with dimethyl carbonate)}

Transesterification of glycerol with DMC was carried out in the liquid phase at 120 0C (Scheme 1). $10 \mathrm{mmol}$ of glycerol and $30 \mathrm{mmol}$ of DMC were taken in a $50 \mathrm{ml}$ two necked round bottom flask equipped with a thermometer. $0.5 \mathrm{~g}$ of Solid base catalyst was added to the reaction mixture and the reaction was carried out at a temperature of $120 \mathrm{0C}$ for $6 \mathrm{~h}$. The solid catalyst was separated from the reaction mixture by centrifugation, and the clear liquid from the reaction mixture was analyzed using GC (Mayura) fitted with a column (10\% SE-30 Chromosorb W-AW, $3 \mathrm{~m} \times 1 / 800)$ coupled with a FID detector by withdrawing the sample every $30 \mathrm{~min}$, and qualitatively analyzed by GC and quantitatively analyzed by GC-MS (Varian).

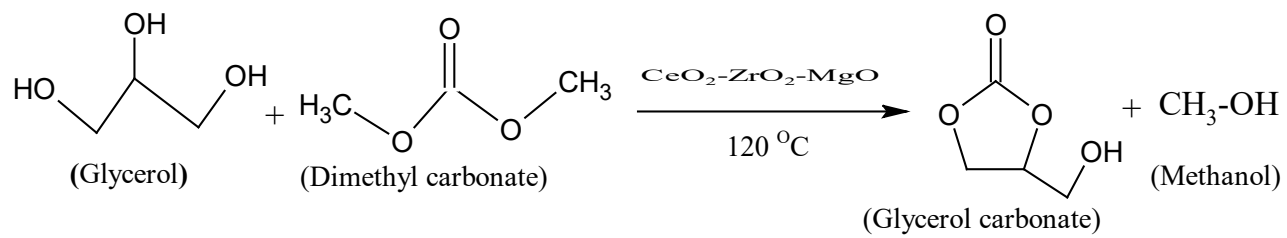

Scheme 1. Transesterfication of glycerol with dimethyl carbonate.

\section{Results and discussion}

\section{$\mathrm{CO}_{2}$ - TPD Analysis}

Among pure oxides, $\mathrm{CeO}_{2}$ was found to be more basic [23]. When ceria and magnesia were mixed, the metal oxide catalyst has both ceria and magnesia basic sites and is more basic than pure ceria and magnesia. Similarly with the impregnation of $\mathrm{Mg}$ (II) ions with ceria-zirconia, the basic sites increases and hence CZM is highly basic. The highest basicity is substantiated by $\mathrm{CO}_{2}$ desorption studied on CZM catalysts. The $\mathrm{CO}_{2}$ desorption profiles of the catalysts are shown in Fig. 1. CZM-111 and CZM-112 shows $\mathrm{CO}_{2}$ desorption peaks in the range of $100-200{ }^{\circ} \mathrm{C}$ as well as $250-400{ }^{\circ} \mathrm{C}$ respectively related to weak and moderate basic sites. However in CZM-113 desorption peak was also observed between $300-400{ }^{\circ} \mathrm{C}$ and 600 $-700{ }^{\circ} \mathrm{C}$ which can be attributed to $\mathrm{CO}_{2}$ desorbed from the sites with a moderate and strong basic strength. The basicity was found to vary with variation of magnesium content in the CZM solid base catalyst. Alkali metal oxides show basicity due to the presence of $\mathrm{M}^{2+}-\mathrm{O}^{2-}$ ion pairs. The metal oxide containing the oxygen ion having low coordination number is considered for the basicity [24]. The high basicity of CZM-113 catalyst can be due to the strong interaction between $\mathrm{MgO}$ with ceria and zirconia. This indicates $\mathrm{CZM}-113$ catalyst having strong basic sites results in high yield of GC, compared to CZM-111 and CZM-112 having weak basic sites. 


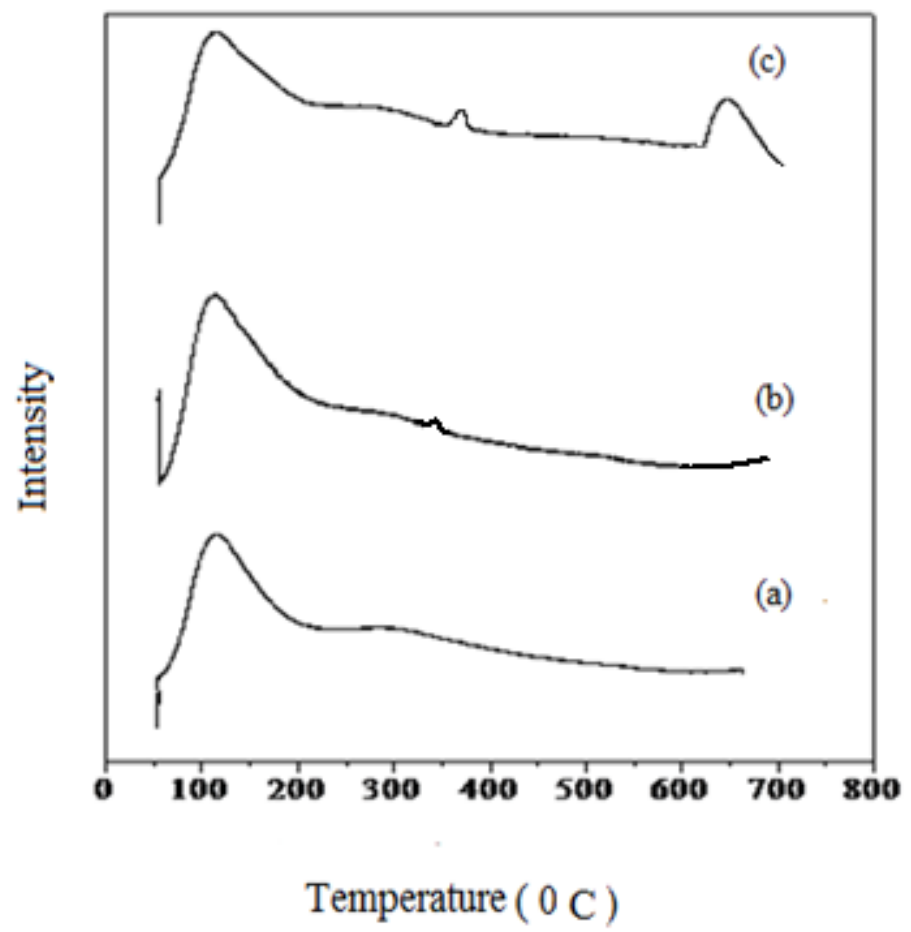

Fig. 1. $\mathrm{CO}_{2}$-TPD Profile of CZM-111, CZM-112 and CZM-113.

\section{PXRD analysis}

The PXRD pattern of CZM-111, CZM-112 and CZM-113 are depicted as Fig 2(a). Pure ceria shows major characterstic reflections at $2 \theta=28.5,33.4,47.3^{0}$ which corresponds to the fluorite structure of ceria Fig. $2 b$. Reflections due to tetragonal phase of zirconia are peaks at $2 \theta=30.2,35.1,50.4,60.0$. MgO exhibits the major reflections at $2 \theta=42.8,62.2^{0}$ corresponding to its rock salt or cubic structure [16, 25]. PXRD pattern of CZM-111, CZM-112 and CZM-113 contains ceria, zirconia, and magnesium peaks. As magnesium loading increases in the catalyst (CZM -113) both tetragonal phase of zirconia and ceria peaks were observed. High content of magnesium doped with ceria and zirconia stabilized tetragonal phase of zirconia. The large no of basic sites available on CZM 113 might be attributed to tetragonal phase of zirconia and these results are confirmed by PXRD pattern $[24,26]$. 

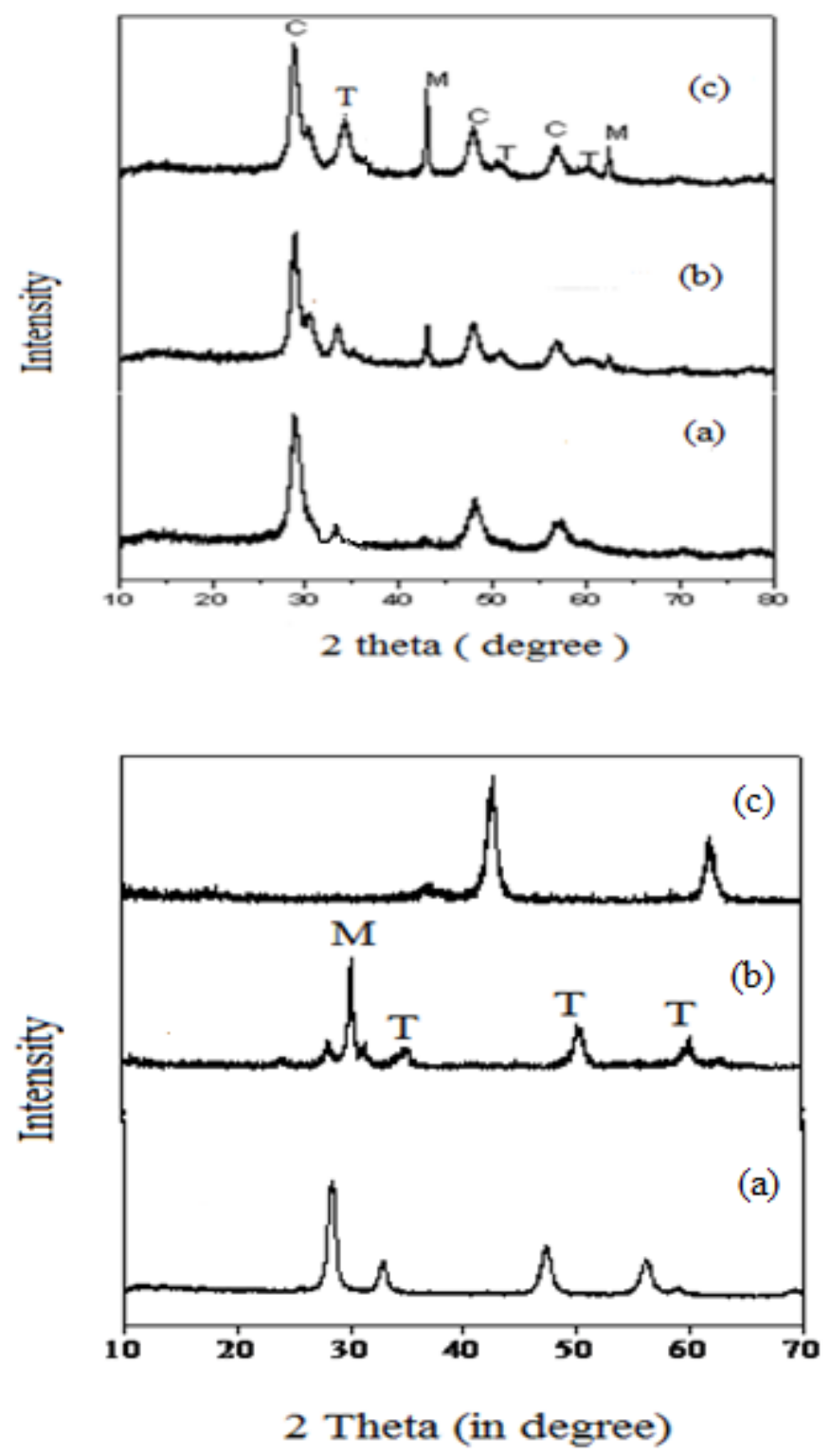

Fig. 2. (a) PXRD Pattern of solid base catalyst (a) CZM-111 (b) CZM-112 and (c) CZM-113. (b) PXRD Pattern of pure metal oxides (a) $\mathrm{CeO}_{2}$ (b) $\mathrm{Z}$ (c) $\mathrm{MgO}$.

\section{FT-IR analysis}

FT-IR spectra of CZM catalysts are represented in Fig. 3. The broad absorption band which appears in the region $3500 \mathrm{~cm}^{-1}$ is due to $\mathrm{OH}$ group and water molecules in the inter layer region [25]. All CZM samples have peaks in the range of $1500-1600$ and $1410-1446 \mathrm{~cm}^{-1}$ due to the deformation mode of the surface $\mathrm{OH}$ group. IR spectrum of each sample exhibits peaks in the range of $1010-1079 \mathrm{~cm}^{-1}$ are due to MO-M bonding ( $\mathrm{M}=\mathrm{Ce}, \mathrm{Mg}, \mathrm{Zr})$ [27]. FT-IR spectra of ceria sample shows a band at $1400 \mathrm{~cm}^{-1}$ is due to Ce$\mathrm{OH}$ stretching vibration in $\mathrm{CeO}_{2}$. Bending and stretching vibrations of $-\mathrm{OH}$ group of water molecules present in the sample shows peaks at $1600 \mathrm{~cm}^{-1}$ and $3500 \mathrm{~cm}^{-1}$. Appearance of band at $1118 \mathrm{~cm}^{-1}$ and $1400-1450 \mathrm{~cm}^{-1}$ in zirconia sample were assigned to $\mathrm{Zr}-\mathrm{O}-\mathrm{Zr}$ and $\mathrm{Zr}-\mathrm{OH}$ stretching and bending modes respectively and thus confirms the formation of zirconia phase. 


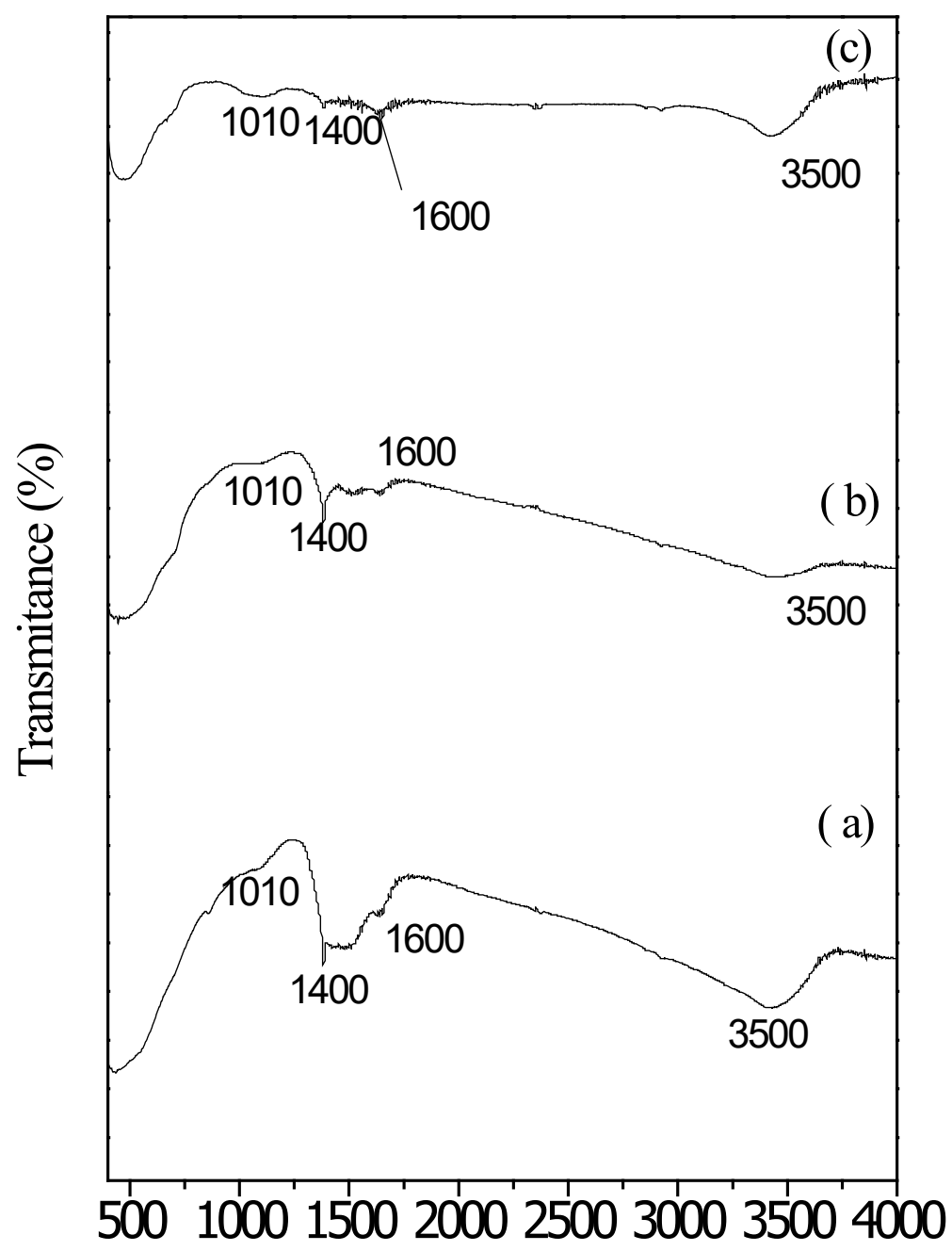

\section{Wave number $\mathrm{cm}^{-1}$}

Fig. 3. FT-IR Analysis of solid base catalysts (a) CZM-111 (b) CZM-112 (c) CZM -113.

\section{ICP-OES analysis}

The elemental analysis carried out via ICP-OES indicated the presence of $0.9 \%, 1.8 \%$ and $2.85 \%$ of Mg (II) in CZM-111, CZM-112 and CZM-113 samples respectively.

\section{Catalytic activity of CZM catalysts towards synthesis of glycerol carbonate}

The CZM catalyst was evaluated for its catalytic activity in the synthesis of glycerol carbonate by transesterification of glycerol with DMC and the results are enumerated in Table 2. In the absence of any catalyst formation of glycerol carbonate was negligible $(<4 \%)$. Catalytic activity of pure metal oxide $(\mathrm{C}, \mathrm{Z}$, $\mathrm{M})$ and bimetal oxide (CZ, CM) is low when compared to tri mixed metal oxide (CZM). The (\%) yield of glycerol carbonate changes with the composition of CZM catalyst. When MgO is incorporated with the mixed oxides the activity of the catalyst increases to give good yield of product probably because of the involvement 
of strong basic sites $[28,29]$. The increase in the percentage yield of glycerol carbonate increases with an increase in the molar concentration of Mg (II) in CZ. CZM-113 has strong basic sites with catalytically active tetragonal phase of zirconia, which is required for better transesterification [25]. These results indicate that the basicity of the catalyst played an important role in obtaining the high yield of glycerol carbonate by transesterification of glycerol with DMC.

Table 1. Catalytic activity of various CZM catalysts to the synthesis of glycerol carbonate used in the present study.

\begin{tabular}{|l|l|}
\hline \multicolumn{1}{|c|}{ Catalyst } & Yield of glycerol carbonate ( \%) \\
\hline $\mathrm{CeO}_{2}$ & 20 \\
\hline $\mathrm{ZrO}_{2}$ & 15 \\
\hline $\mathrm{MgO}$ & 30 \\
\hline $\mathrm{CeO}_{2}-\mathrm{ZrO}_{2}$ & 35 \\
\hline $\mathrm{CeO}_{2}-\mathrm{MgO}$ & 42 \\
\hline $\mathrm{CZM}-111$ & 66 \\
\hline $\mathrm{CZM}-112$ & 88 \\
\hline $\mathrm{CZM}-113$ & 97 \\
\hline
\end{tabular}

[Reaction condition: $10 \mathrm{~m} \mathrm{~mol}$ of glycerol and $30 \mathrm{~m} \mathrm{~mol} \mathrm{of} \mathrm{DMC,} 0.5 \mathrm{~g}$ catalyst, $6 \mathrm{~h}]$.

\section{Effect of molar ratio of the reactants (Glycerol: DMC)}

Transesterification of glycerol with DMC was evaluated by varying the molar ratio of the reactants from 1: 3 to 3:1. The effect of molar ratio of glycerol to DMC was examined using CZM (1:1:3) and the results are depicted in Fig. 4. It was observed that lower the glycerol to DMC ratio (1:1), GC formation is less due to decarboxylation (preferred over transesterfication) and results are in accordance with previous reports $[24,27,30]$. A maximum yield of glycerol carbonates (97\%) was achieved with 1:3 molar ratio. A further increase in the molar ratio beyond 1:3 leads to the insolubility of DMC and hence no increase in yield was observed [31,33].

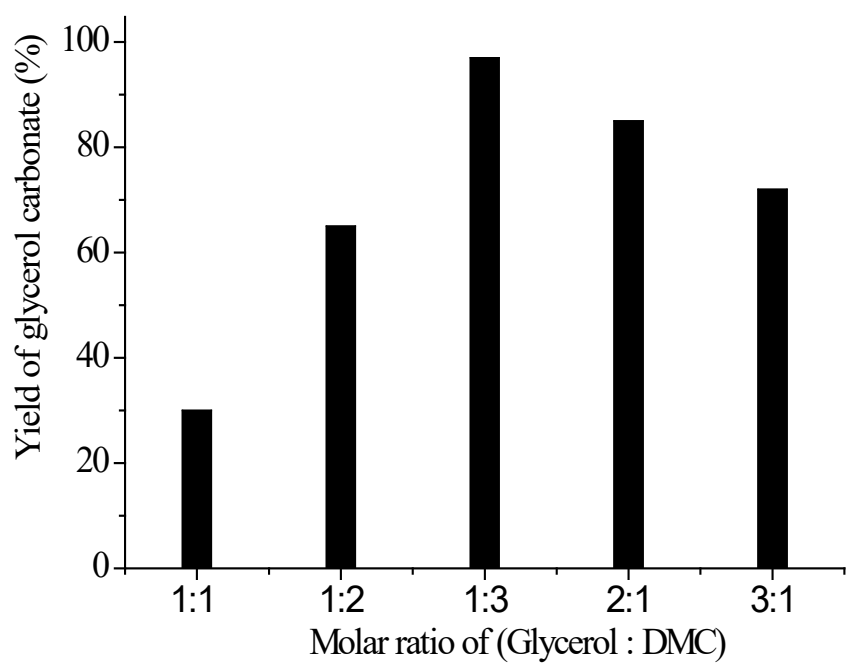

Fig. 4. Effect of molar ratio (Glycerol: DMC) of the reactants. [Reaction condition: $0.5 \mathrm{~g}$ catalyst, $6 \mathrm{~h}, 120$ ${ }^{\circ} \mathrm{C}$.]. 


\section{Effect of reaction temperature}

Effect of reaction temperature on the transesterification of glycerol with DMC was studied by varying the temperature from $100{ }^{\circ} \mathrm{C}$ to $140{ }^{\circ} \mathrm{C}$ and results are enumerated as Fig. 5. The catalyst $\mathrm{CZM}-113$ showed highest catalytic activity at $120^{\circ} \mathrm{C}$. As the reaction temperature was increased above $120{ }^{\circ} \mathrm{C}$, there is a decrease in the yield of glycerol carbonate which may be due to the side reactions [34]. Hence the optimum temperature $120^{\circ} \mathrm{C}$ is used for the present study $[35,36]$.

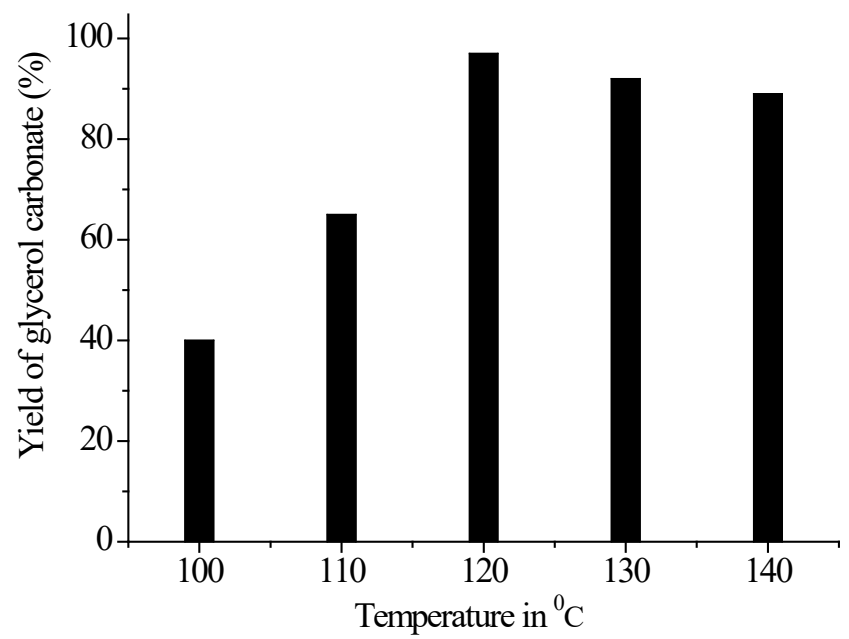

Fig. 5. Effect of temperature on glycerol carbonate yield [Reaction condition: $10 \mathrm{mmol}$ of glycerol and 30 mmol of DMC, $0.5 \mathrm{~g}$ catalyst, $6 \mathrm{~h}]$.

\section{Effect of weight of catalyst}

Transesterification of glycerol with DMC was studied by varying the weight of catalyst from $0.1 \mathrm{~g}$ to $0.7 \mathrm{~g}$ and the results are shown in Fig. 6. The yield of glycerol carbonate increases with an increase in the weight of the catalyst from 0.1 to $0.5 \mathrm{~g}$ which may be due to the availability of more number of active sites on the catalyst for the reaction. Maximum yield of glycerol carbonate was obtained when the weight of the catalyst was $0.5 \mathrm{~g}$. As the weight of the catalyst was increased above $0.5 \mathrm{~g}$, the yield of glycerol carbonates decreases it may be due to the lower dispersion of the catalyst in the reaction medium [24].

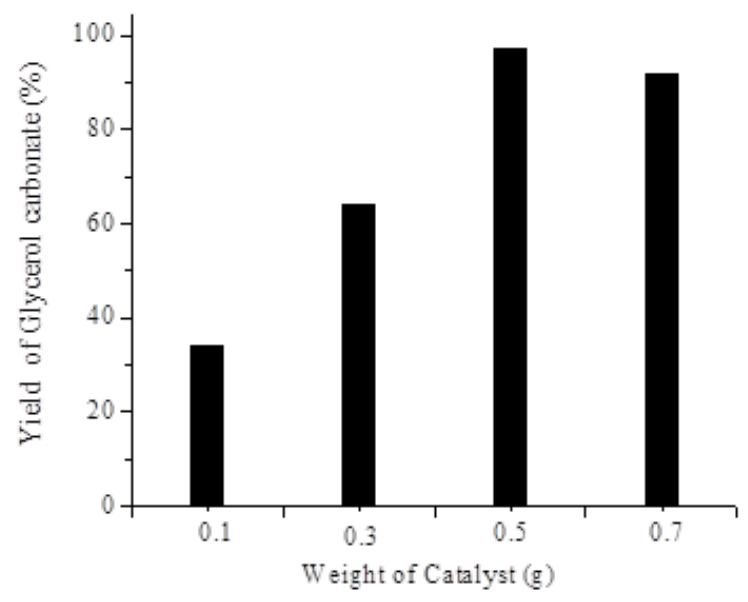

Fig. 6. Effect of weight of the catalyst in the synthesis of glycerol carbonate [Reaction condition: $10 \mathrm{mmol}$ of glycerol and $30 \mathrm{mmol}$ of DMC, $0.5 \mathrm{~g}$ catalyst, $6 \mathrm{~h}$ ]. 


\section{Effect of reaction time}

Effect of reaction time on the transesterification of glycerol with DMC was studied by varying the reaction time period from $1 \mathrm{~h}$ to $7 \mathrm{~h}$ and the results are depicted in Fig. 7. Yield of glycerol carbonate increases with an increase in the time from $1 \mathrm{~h}$ to $6 \mathrm{~h}$ and reaches a maximum yield of glycerol carbonate $(97 \%)$ at $6 \mathrm{~h}$. After $6 \mathrm{~h}$ the glycerol carbonates yield decreases due to decarboxylation by the strong basic site which is in accordance with literature [30].

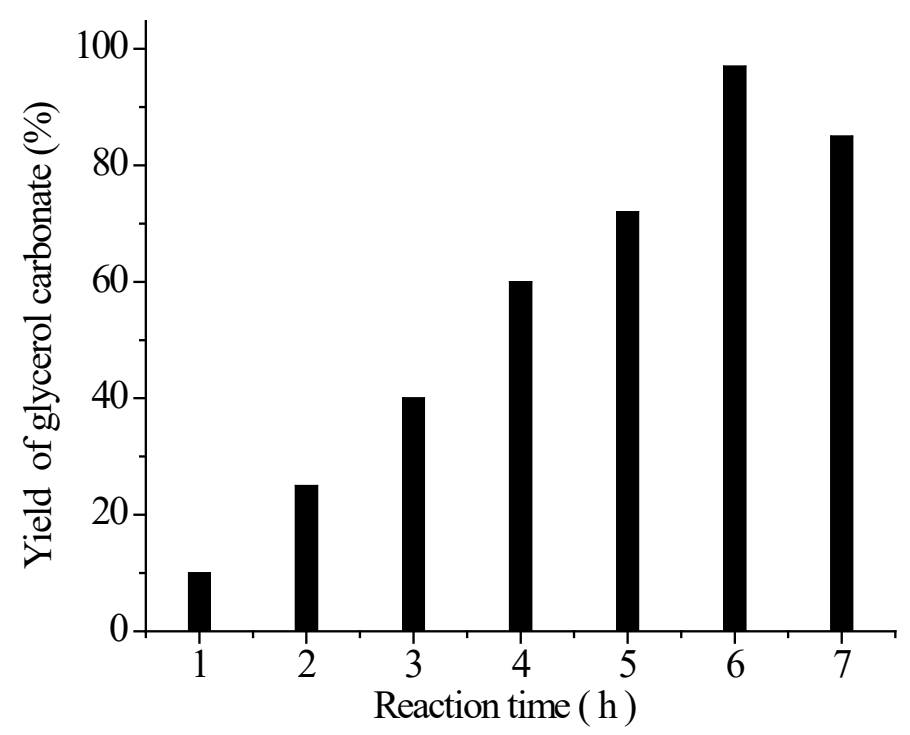

Fig. 7. Effect of reaction time on the synthesis of glycerol carbonate [Reaction condition: $\quad 10 \mathrm{~m}$ mol of glycerol and $30 \mathrm{mmol}$ of DMC, $0.5 \mathrm{~g}$ catalyst, $6 \mathrm{~h}]$.

\section{Reusability of the catalyst}

Catalyst reusability is the main parameter with respect to a heterogeneous catalyst. After the first reaction cycle, the catalyst was filtered from the reaction mixture, washed with water and acetone to remove any adsorbed products on the surface of the catalyst and dried in an oven at $120{ }^{\circ} \mathrm{C}$ for $1 \mathrm{~h}$ and calcined at 650 ${ }^{0} \mathrm{C}$ for $1 \mathrm{~h}$. Resultant catalyst was reused for next reaction cycle. It was observed that there is no change in the activity of the CZM-111, CZM-112, and CZM-113 catalysts up to four reaction cycles. The results are enumerated as Fig. 8. 


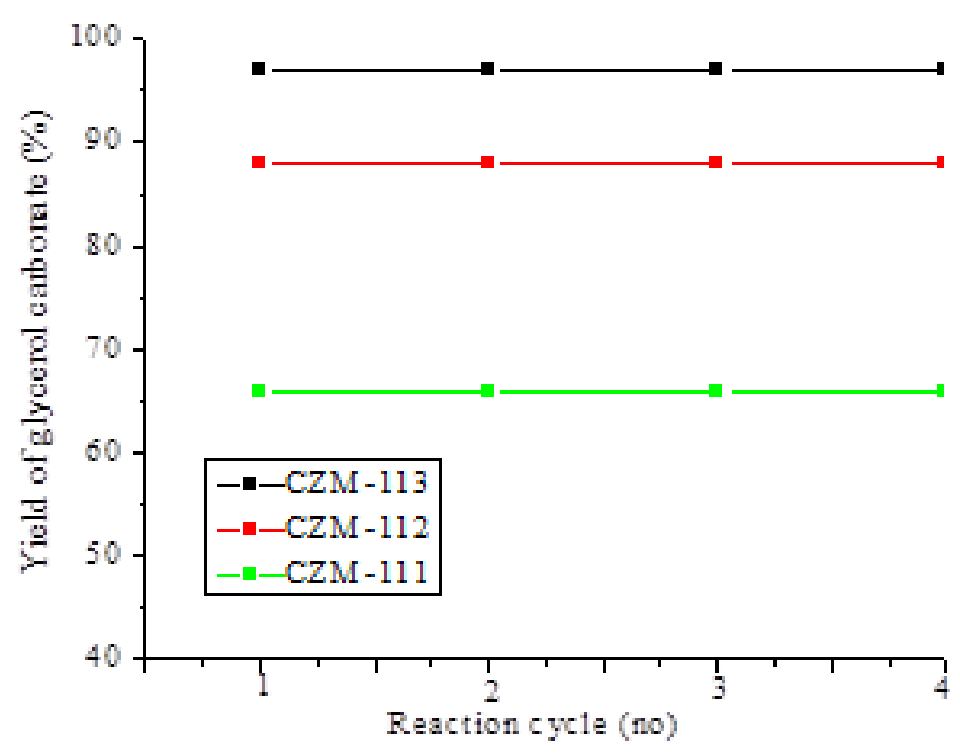

Fig. 8. Reusability of CZM catalysts.

\section{Mechanism for the synthesis of glycerol carbonate}

A plausible reaction mechanism for the base catalysed transesterification of glycerol with dimethyl carbonate towards the synthesis of glycerol carbonate is given in Scheme 2. In the first step hydroxyl group of glycerol molecule reacts with base which results in the formation of glyceroxide ion. The intermediate glyceroxide ion attack carbonyl group of DMC resulting in the formation of another intermediate carbonate molecule. In the last step the intermediate carbonate molecule gets rearranged to form a glycerol carbonate with the elimination of an alkoxide ion. Finally, the alkoxide ion combines with the protonated base to give back alcohol and base catalyst (inset of Scheme 2). A similar mechanism for the base catalyzed transesterification has been reported by Jose, et al and Prakuthi, et al [37, 33].

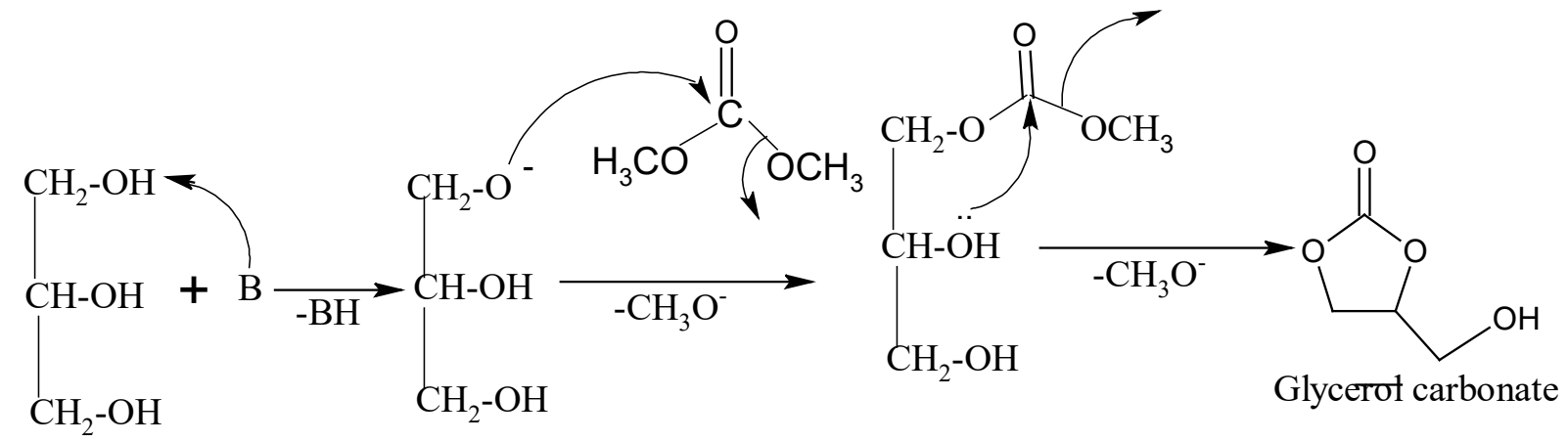

Glycerol

$$
\mathrm{CH}_{3} \mathrm{O}^{-}+\mathrm{BH} \longrightarrow \mathrm{CH}_{3} \mathrm{OH}+\mathrm{B}
$$

Scheme 2. Mechanism of base catalyzed transesterification reaction of glycerol with DMC to produce GC. 


\section{Conclusions}

Ceria-Zirconia-Magnesium mixed metal oxide is an excellent catalyst for the transesterification of glycerol with dimethyl carbonate for the synthesis of glycerol carbonate. The activity of this mixed oxide was found to depend on mole composition of the individual oxides. Ceria-zirconia-magnesium with a mole composition of 1:1:3 was found to be more efficient than the other compositions such as bimetallic oxides and mono metal oxides. Ceria-Zirconia-Magnesium catalyst with composition 1:1:3 calcined at $650{ }^{0} \mathrm{C}$ exhibited highest transesterification activity due to the presence of a greater number of strong basic site with more catalytically active tetragonal phase. A correlation between the surface basicity and the catalytic activity of ceria catalysts was observed. The highest yield of GC up to (97\%) was obtained when the reaction temperature was $120{ }^{\circ} \mathrm{C}$ with the mole ratio of the reactant $1: 1: 3$ in presence of $0.5 \mathrm{~g}$ of CZM solid base catalyst. Ceria-zirconia-magnesium catalyst was found to be reusable atleast for four reaction cycles.

\section{Acknowledgements}

Authors are thankful to Vision Group on Science and Technology, Government of Karnataka (GRD375/2014-15) for funding. Authors are also thankful for Poornaprajna Institute of Scientific Research, Bangalore for PXRD and FT-IR analysis and CO2-TPD Analysis.

\section{References}

1. Marakatti, S, V.; Anand Halgeri B.; RSC Adv, 2015, 5, 14286-14293.

2. Tanb, Y. Z.; Liu, J.; Wang, Kang, M.; Yin, N.; Wang, X.; Zhub, Y.; J. Braz. Chem. Soc, 2014, 25, 152-160.

3. Burk, R. M.; Roof, M. B.; Tetrahedron Lett, 1993, 34, 395-398.

4. Mizuno, T.; Nakai, T.; Mihara, M.; Heteroat. Chem, 2010, 21, 99-102.

5. Hu, J.; Li, J.; Gu, Y.; Guan, Z.; Ni, W.; Li, Y.; Li, T.; Appl. Catal. A: Gen, 2010, 386, 188- 193.

6. Vieville, C.; Yoo, J.; Pelet, S.; Mouloungui, Z.; Catal. Lett, 1998, 56, 245-247.

7. George, J.; Patel, Y.; Pillai, S.M.; Munshi, P.; J. Mol. Catal. A: Chem, 2009, 304, 1-7.

8. Climent, M.J.; Corma, A.; Frutos, P. D.; Iborra, S.; Noy, M.; Velty, A.; J. Catal, 2010, 269, 140-149.

9. Hammond, C.; Lopez-Sanchez, J. A.; Rahim, M. H. A; Dimitratos, N.; Jenkins, R. L.; Carley, A. F.; He, Q.; Kiely C. J.; Knight, D.W.; Hutchings, G.J.; Dalton Trans, 2011, 40, 3927-3937

10. Ochoa-Gómez, J.R; Gómez-Jiménez-Aberasturi, O.; Maestro-Madurga, B.; Pesquera- Rodríguez A.; Ramírez-López, A. C.; Lorenzo-Ibarreta L.; Torrecilla-Soria, J.; Villarán-Velasco, M. C.; Appl. Catal. A: Gen, 2009, 366, 315-324.

11. Bell, J. B.; US Pat, 1959, 2, 915 -529.

12. Alvarez, M. G.; Segarra, A. M.; Contreras, S.; Sueiras, J. E.; Medina, F.; Figueras, F.; Chem. Eng. J, 2010, 161, 340-345.

13. Bai, R.; Wang, Y.; Wang, S.; Mei, T.; Li, G.; Li, Fuel Process. Technol, 2010, 106, 209-214.

14. Bancquart, S.; Vanhove, C.; Pouilloux, Y.; Barrault, J.; J. Appl. Catal. A: Gen, 2001,218, 1-11

15. Sato, S.; Sato, F.; Gotoh, H.; Yamada, Y.; ACS Catal, 2013, 3, 721-734.

16. Venkatesh, Mohammed Shamshuddin, S. Z.; Shyamsundar, M.; Vasanth, V. T.; J. Mex. Chem. Soc, 2014, 58, 378-385.

17. Gotoh, H.; Yamada, Y.; Sato, S.; Appl. Catal. A: Gen, 2010, 377, 92-98.

18. Sakata, Y.; Ponec, V.; Appl. Catal. A: Gen, 1998, 166, 173-184.

19. Kobune, M.; Sato, S.; Takahashi, R.; J. Mol. Catal. A: Chem,2008, 279, 10-19.

20. Rathod, S.; Arbad, B.; Lande, M.; Chinese J of Catal, 2010, 31, 631-636. 
21. Trovarelli, A.; catalysis by ceria and related materials London, 2013, 12, 1-888.

22. Rathod, B. S.; Machhinndra, K.; Lande, R.; Balasaheb, Arbad, Gambhire, A.; Arabian J of Chem, 2014, 7, 373-378.

23. Hussein, A.; Khalaf, Springer plus, 2013, 2:619, 1-9.

24. Parameswaram, G.; Srinivas, M.; HariBabu, B.; Sai Prasad, P. S.; Lingaiah, N.; Catal. Sci. Technol, 2013, 3, 3242-3249.

25. Malyaadri, M.; Jagadeeswaraiah, K.; Sai Prasad P. S.; Lingaiah, N.; Catalysts. Appl.Catal. A: Gen, 2011, 401, 153-157.

26. Peterson Santos Querino, Jose Renato Carlos Bispo, Maria do Carmo Rangel, Catalysis Today, 2005, 107, 930-925.

27. Rathoda, S.; Navgireb, M.; Arbadb, B.; Lande, M. S.; Afr. J. Chem, 2012, 65, 196-201.

28. Hattori H.; Chem Rev, 1995, 95, 537-558.

29. Tsuji H.; Hattori H.; Catal Today, 2006, 116, 239-243.

30. Okoye, P. U.; Abdullah, Z. B.; Hameed, H.; J. Taiwan Institute of Chem. Eng, 2016, 68, 51-58.

31.Zheng, L.; Xia, S.; Lu, X. Z.; Hou, Z.; Chinese. J. Catal, 2015, 36, 1759-1765.

32. Khayoon, M.S.; Hameed, B.H.; Appl Catal A Gen, 2013, 466, 272-281.

33. Prakruthi, H. R.; Jai Prakash, B. S.; Bhat, Y. S.; J. Mol. Catal. A: Chem, 2015, 408, 214-220.

34. Liu, J.; Li, Y.; Zhang, J.; He, D. App Catal A: Gen, 2016, 513. 9-18.

35. Cinzia Chiappe.: Sunita Rajamani: Pure Appl. Chem, 2012, 84, 755-762.

36. Yin Wang: Chunling Liu: Jihong Sun: Rongzhen Yang: Wensheng Dong.: Sci. china chem., 2015, $58,708-71$.

37. Jose, R.; Gomez, C.; Go, O. Aberasturi, M. N. J.; Madurga, B. M.; Rodrıguez, A. P.; Lopez, C. R.; Ibarreta, L. L.; Soria, J. T.; Velasco, C. M. V.; App Catal A: Gen, 2009, 366, 315-324. 